\title{
Meningovertebral ligaments as a cause for difficult epidural placement in a child: identification using epidurography
}

\author{
Clyde T. Matava, MBChB, DA, MMed, MHSC 두 - Yuvaraj Kotteeswaran, MD, DNB
}

Received: 28 October 2019/Revised: 11 January 2020/Accepted: 16 January 2020/Published online: 24 January 2020

(C) Canadian Anesthesiologists' Society 2020

Epidural anesthesia can provide excellent surgical conditions and postoperative pain management. In the event of epidural placement failure, however, the cause must be accurately and efficiently identified and addressed. Having obtained written consent from the patient's parents, we describe the use of epidurography for identifying meningovertebral ligaments as a cause for difficult epidural placement in a child.

A seven-year-old patient with cerebral palsy, central apnea, and a previous thoracic (T3) compression fracture presented for wide resection of a right femoral osteosarcoma. During epidural catheterization (under general anesthesia), difficulty was encountered when inserting the epidural catheter. At the L3/L4 level, the catheter could be threaded in only $2 \mathrm{~cm}$ past the needle tip before meeting resistance. In addition, at the L2/L3 level, the catheter threaded in only $0.5 \mathrm{~cm}$, with significant resistance. Hence, both catheters were removed. Epidurography was then performed (through the epidural catheter) with the needle insertion site at L2/L3. It revealed a pattern suggesting caudal spread of the contrast (Figure A). The epidural attempt was repeated at L3/L4 under epidurography guidance, which showed caudally directed coiling of the epidural catheter (Figure B). It also revealed that a horizontal meningovertebral ligament prevented both cephally directed passage of the epidural catheter and spread of the contrast. Concerned that any local anesthetic injected would not spread above the L2/L3 level, we pulled the catheter back until the tip was near the apex of the original coil. Repeated epidurography then showed adequate spread of contrast via the anterior

C. T. Matava, MBChB, DA, MMed, MHSC ( $\varangle)$.

Y. Kotteeswaran, MD, DNB

Department of Anesthesia and Pain Medicine, The Hospital for

Sick Children, Toronto, ON, Canada

e-mail: clyde.matava@sickkids.ca

Department of Anesthesia, Faculty of Medicine, University of Toronto, Toronto, ON, Canada epidural space (Figure C). We elected to use a lowconcentration, high-volume epidural solution $(0.0625 \%$ bupivacaine with 1:500,000 epinephrine) infused at a rate $0.5 \mathrm{~mL} \cdot \mathrm{kg}^{-1} \cdot \mathrm{hr}^{-1}$ to help facilitate adequate spread. The epidural infusion provided excellent analgesia for up to 80 $\mathrm{hr}$ postoperatively in this patient who was not a suitable candidate for patient-controlled analgesia. There were no adverse events related to the epidural technique.

Dorsal meningovertebral ligaments are found between the dural sac and ligamentum flavum or lamina, and up to $44 \%$ are reported at the L3/L4 interspace. ${ }^{1}$ These ligaments may obstruct the advance of an epidural catheter, resulting in a high incidence of catheter coiling, and causing uneven distribution of local anesthetic solution - all contributing to epidural failure. Epidural hemorrhage during spinal surgery has also been reported in the presence of these placed ligaments. ${ }^{2}$ Despite epidural loss of resistance, failure to advance an epidural catheter has been reported in up to $4.5 \%$ of cases. ${ }^{3}$ Epidurography can be used to assist with the troubleshooting of difficult epidural catheter placement.

Conflicts of interest None.

Funding statement This article did not receive funding.

Editorial responsibility This submission was handled by Dr. Hilary P. Grocott, Editor-in-Chief, Canadian Journal of Anesthesia.

Ethics Written consent was obtained to publish this case report.

\section{References}

1. Jiang $H$, Shi $B, X u S$. An anatomical study of lumbar epidural catheterization. BMC Anesthesiol 2015. DOI: https://doi.org/10. 1186/s12871-015-0069-x.

2. Savolaine ER, Pandya JB, Greenblatt SH, Conover SR. Anatomy of the human lumbar epidural space: new insights using CTepidurography. Anesthesiology 1988; 68: 217-20. 


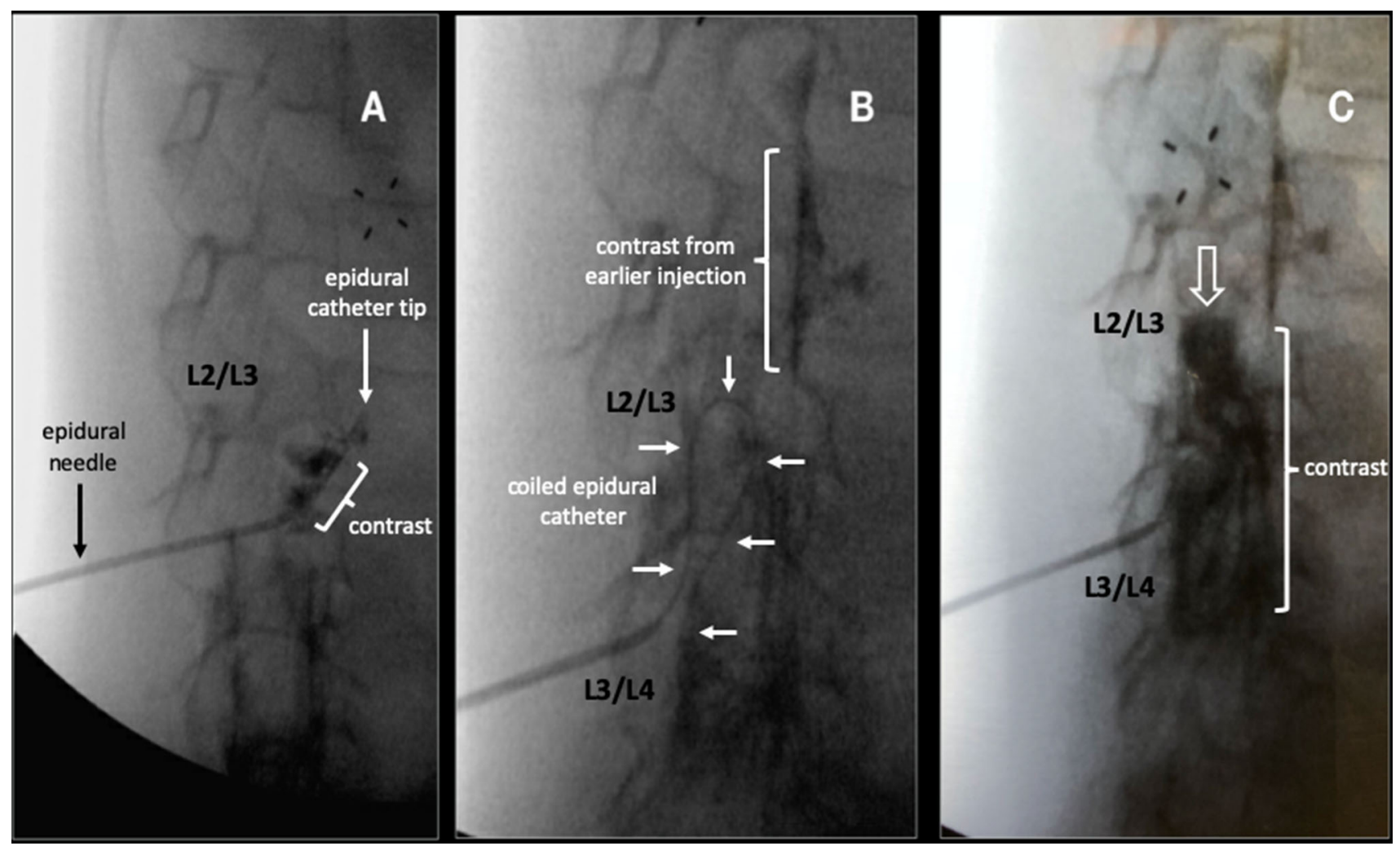

Figure A) Epidurography was conducted with $0.5 \mathrm{~mL}$ of the nonionic contrast agent Omnipaque (Iohexol) 300 (GE Healthcare, Cork, Ireland) injected through an epidural catheter that was advanced through a $18 \mathrm{G}$ Touhy needle inserted at L2/L3. The contrast agent is seen to spread caudally. B) Epidurography was conducted with 1.0 $\mathrm{mL}$ of contrast agent injected through the epidural catheter to assist with visualization of the epidural catheter. The catheter, advanced

3. Sviggum HP, Farber MK. The incidence and management of inability to advance ArrowFlexTip Plus epidural catheters in obstetric patients. Int J Obstet Anesth 2014; 23: 113-7. through the epidural needle placed at the L3/4 level, is coiled (multiple arrows) at the L2/L3 level, with the catheter tip located at L3/L4. Contrast agent from the previous epidural placement and epidurography attempt is also seen. C) Epidurography conducted with $1.0 \mathrm{~mL}$ of contrast agent depicts the well-delineated horizontal structure of a meningovertebral ligament (open arrow) that blocks cephalad spread of the contrast within the epidural space at L2/L3.

Publisher's Note Springer Nature remains neutral with regard to jurisdictional claims in published maps and institutional affiliations. 